\title{
Adaptation of the AFRC wheat phenology model for Dutch conditions
}

\author{
K. Reinink ${ }^{1}$, 1. Jorritsma and A. Darwinkel
}

Research Station for Arable Farming and Production of Field Vegetables (PAGV), P.O. Box 430, 8200 AK Lelystad, Netherlands

Received 11 April 1985; accepted 26 April 1985

Key words: development, growth stage, model, phenology, simulation, sowing date, wheat

\begin{abstract}
The AFRC model describes the phenology of the wheat plant in relation to its environment. Its elements are a description of the effects of temperature, vernalization and photoperiod on development. In 1976-79 four sowing date experiments were carried out in which the developmental stages of the various sowings were scored at regular time intervals. Two of these experiments, containing 35 sowings of a single variety in two seasons, were used to evaluate and improve the model. Variation in prediction of anthesis was used as a measure of the 'success' of the model. The unchanged AFRC model predicted anthesis with a coefficient of variation of $5.0 \%$. After several parameter changes this value was reduced to $2.8 \%$. When the adapted model was used to predict all developmental stages that were scored in all four experiments, it gave good results for anthesis and maturity. Coefficients of variation were high for stages before stem elongation. Exclusion of extreme sowing dates improved the results of the model.
\end{abstract}

\section{Introduction}

In the life cycle of a cereal plant many distinct phases can be recognized. To describe these phases, various scales have been proposed. Most scales are based on external plant characteristics, which can be distinguished without dissection of the plant, for example the Feekes scale (Feekes, 1941) and the Decimal Code (Zadoks et al., 1974). These plant characteristics are the result of two separate but connected processes: growth and development. Growth can be defined as the process of the net accumulation of biomass. Development phases are characterized by the order and rate of appearance of vegetative and reproductive plant organs. The dis-

1 Present address: Institute for Horticultural Plant Breeding (IVT), P.O. Box 16, 6700 AA Wageningen, Netherlands. 
tribution pattern of assimilates within the plant is strongly related to and possibly governed by the developmental stage. Externally observed development is the result of the activity of the shoot apex, which displays an increasing complexity during development (Kirby \& Appleyard, 1982a).

In the past decades models have been formulated to simulate the growth of many crops. For cereals, dynamic models have been used to investigate water use and nitrogen nutrition (van Keulen \& Seligman, in prep.) and to calculate damage relations for pests and diseases (Rabbinge et al., 1983). In these models the partitioning of assimilates between plant organs is considered as a function of developmental stage. Therefore the developmental stage of the crop must be predicted with reasonable accuracy. Because of the strong influence of environmental conditions upon plant development there is a need for exact descriptions of the relationship between development and prevailing environmental conditions.

Many studies have concentrated on this relationship. Leaf and tiller appearance (Decimal Codes 10-29) have been shown to be linear with respect to temperature (Baker et al., 1980). Vos (1981) showed duration of the post-anthesis phase (Decimal Codes 61-99) to be linearly correlated with temperature. For the pre-anthesis period apex development was found to be influenced also by effects of vernalization and length of photoperiod (Ahrens \& Loomis, 1963; Chujo, 1966; Gott, 1957; Halloran \& Pennell, 1982; Hänsel, 1953; Trione \& Metzger, 1970). Both effects are dependent on variety and are more marked in their influence on the phenological development of winter wheat than on spring wheat varieties. The length of the successive phases from double ridge to anthesis is linearly related to apex development, but not always to the number of leaves or tillers (Kirby \& Appleyard, 1982b).

Attempts have been made to integrate results of such studies in descriptive simulation models which can be used for prediction purposes. The simplest models only use temperature data (e.g. Van Keulen \& Seligman, in prep.); the duration of the successive development phases is a simple function of specific temperature sums, that is to say, calendar time is replaced by the concept of thermal time. In this approach effects of vernalization and length of photoperiod are neglected. Two detailed models, which incorporate these effects, are the TAMW model, developed in Texas (Maas \& Arkins, 1980), and a model developed in England by the Agricultural and Food Research Council (AFRC) (Weir et al., 1984). In our simulations the AFRC model has been used as a starting point. This model was preferred to the TAMW model because of its relative simplicity and the availability of a good description of all input parameters. It was also expected to have a greater suitability for Western European wheat growing conditions.

The objective of this paper is an evaluation and adaptation of the AFRC phenology model for Dutch wheat varieties and circumstances. The data used for validation were collected from field experiments. With the adjusted model, an attempt was made to relate development stages to thermal time as calculated by the phenology model. 


\section{Short description of the AFRC model}

A detailed description of the AFRC wheat phenology model is given by Weir et al. (1984). In the AFRC phenology model Julian time is replaced by thermal time ( $\mathrm{Tt}$ ). This $\mathrm{Tt}$ is a time integral of daily temperature and is calculated as the sum of temperatures above a certain minimum with multiplicative effects for vernalization and photoperiodic effects introduced for appropriate phases. The time step of the model is one day so $\mathrm{Tt}$ has the dimension ${ }^{\circ} \mathrm{C}$-day $\left({ }^{\circ} \mathrm{C} \cdot \mathrm{d}\right)$.

The variables input into the model are site latitude, the sowing date and daily minimum and maximum air temperatures at $1.5 \mathrm{~m}$. The state of vernalization is represented as a continuous variable $(\mathrm{Fv})$, with values between 0 (no vernalization) and 1 (fully vernalized). The vernalization requirement for a specific cultivar is represented as the number of days at optimal vernalization temperature range needed for complete vernalization (Vsat).

The effect of temperature on the vernalization process is given in a vernalizationtemperature response (VTR) curve (Fig. 1a). The vernalization process starts at germination but the correction for the state of vernalization to the rate of thermal time accumulation starts at emergence and ends when an Fv value of 1 is reached. At double ridge stage vernalization is considered to have ended and Fv is set to 1 for the rest of the development.

Photoperiodic effects are assumed to affect the crop from emergence to anthesis. The correction factor for photoperiod $(\mathrm{Fp})$ varies between 0 and 1 , with a linear increase in Fp between a basal photoperiod of 0 hours (before double ridge stage) or 7 hours (after double ridge) and a saturating photoperiod of 20 hours (Lumsden, 1980).

\section{Field data}

From 1976 to 1979 four sowing date experiments were carried out on a newly reclaimed marine clay soil at Lelystad. The plots were adequately fertilized and water shortage is not thought to be a problem on these soils. Three wheat varieties were used: in the first season (1976-77) the winter wheat variety Lely (6 sowing dates), in 1977-78 the winter wheat variety Caribo (28 sowing dates) and in 1978-79 the winter wheat variety Caribo ( 7 sowing dates) and the spring wheat variety Toro ( 9 sowing dates). The sowing dates and the number of days from sowing to reach a number of development stages are given in Table 1. Development stages were scored at least once a week. Anthesis and maturity were determined at two-day or three-day intervals. Two methods were used to determine maturity; in 1977 the stage at which kernel water content was $35 \%$ or less, was scored as maturity. This method is rather laborious and not always accurate. Therefore in the next two years this stage was determined by means of a colouring test (Feiffer et al., 1977). For this test an ear sample, cut just above the highest node, was placed in an eosine solution. Maturity was scored when $50 \%$ of the sampled ears showed no more transport of the dye into the ear. Weather data were collected at an automatic weather station located 7 $\mathrm{km}$ from the experimental fields. 


\section{K. REININK, I. JORRITSMA AND A. DARWINKEL}

Table 1. Sowing dates (S) and the number of days from sowing to the successive development stages (Decimal Code). Results of 4 field experiments. Explanation of growth stages: E: emergence, 21: main shoot and 1 tiller, 30: pseudostem erection, 31: first node detectable; 32: second node detectable; 39 : flag leaf ligule just visible, 45: boots swollen, 61: beginning of anthesis, 91 : maturity.

\begin{tabular}{|c|c|c|c|c|c|c|c|c|c|c|c|c|c|c|c|c|c|}
\hline \multirow[b]{2}{*}{$S$} & \multicolumn{7}{|c|}{$\begin{array}{l}1976-1977 \\
\text { Lely winter wheat }\end{array}$} & \multirow[b]{2}{*}{ S } & \multicolumn{9}{|c|}{$\begin{array}{l}1977-1978 \\
\text { Caribo winter wheat }\end{array}$} \\
\hline & $\mathrm{E}$ & 21 & 30 & 31 & 39 & 61 & 91 & & $\mathrm{E}$ & 21 & 30 & 31 & 32 & 39 & 45 & 61 & 91 \\
\hline 901 & 4 & 16 & 64 & 204 & 247 & 285 & 338 & 831 & 8 & 19 & 54 & 204 & 221 & 258 & 272 & 279 & 337 \\
\hline 1001 & 6 & 20 & 136 & 209 & 231 & 257 & 310 & 907 & 9 & 20 & 60 & 202 & 218 & 252 & 265 & 272 & 330 \\
\hline 1101 & 20 & 108 & 179 & 188 & 210 & 232 & 282 & 914 & 10 & 21 & 79 & 200 & 217 & 247 & 259 & 265 & 323 \\
\hline 1201 & 58 & 104 & 157 & 166 & 185 & 205 & 254 & 921 & 9 & 24 & 114 & 199 & 216 & 242 & 253 & 259 & 317 \\
\hline 103 & 42 & 79 & 129 & 137 & 154 & 174 & 222 & 928 & 11 & 25 & 152 & 197 & 212 & 237 & 246 & 252 & 310 \\
\hline \multirow[t]{3}{*}{201} & 33 & 61 & 106 & 114 & 130 & 151 & 195 & 1005 & 10 & 27 & 181 & 196 & 209 & 232 & 240 & 246 & 304 \\
\hline & \multirow{2}{*}{\multicolumn{7}{|c|}{$\begin{array}{l}1978-1979 \\
\text { Caribo winter wheat }\end{array}$}} & 10 & 12 & 37 & 185 & 195 & 205 & 226 & 233 & 239 & 297 \\
\hline & & & & & & & & 9 & 11 & 41 & 183 & 192 & 201 & 222 & 229 & 235 & 294 \\
\hline & & & & & & & \multirow{3}{*}{91} & & & & & & & & & & 281 \\
\hline \multirow{2}{*}{$S$} & \multirow{2}{*}{$\mathrm{E}$} & \multirow{2}{*}{21} & \multirow{2}{*}{39} & \multirow{2}{*}{\multicolumn{2}{|c|}{45}} & \multirow{2}{*}{61} & & 92 & 18 & 85 & $1 / 7$ & 183 & 190 & 208 & 214 & 221 & 280 \\
\hline & & & & & & & & 1109 & 35 & 117 & 171 & 177 & 183 & 201 & 207 & 214 & 274 \\
\hline 920 & 8 & 25 & 251 & & 58 & 267 & 319 & 1116 & 41 & 113 & 165 & 171 & 177 & 195 & 201 & 208 & 268 \\
\hline 1004 & 9 & 29 & 239 & & 46 & 255 & 30 & 1123 & 40 & 110 & 159 & 165 & 170 & 188 & 194 & 202 & 261 \\
\hline 1019 & 13 & 72 & 226 & & 35 & 243 & 29 & 1130 & 36 & 109 & 153 & 158 & 164 & 182 & 188 & 195 & 254 \\
\hline 1103 & 18 & 156 & 213 & 22 & 23 & 231 & 284 & 1207 & 36 & 104 & 147 & 152 & 157 & 175 & 181 & 189 & 248 \\
\hline 1120 & 87 & 145 & 198 & 20 & 09 & 216 & 271 & 1214 & 46 & 100 & 142 & 146 & 152 & 169 & 175 & 183 & 241 \\
\hline 1227 & 89 & 119 & 164 & & 75 & 183 & 237 & 1221 & 51 & 97 & 136 & 140 & 146 & 161 & 168 & 176 & 234 \\
\hline \multirow[t]{4}{*}{306} & 32 & 60 & 106 & & 15 & 123 & 175 & 1228 & 63 & 97 & 131 & 135 & 140 & 155 & 162 & 170 & 228 \\
\hline & \multirow{3}{*}{\multicolumn{7}{|c|}{$\begin{array}{l}\text { 1978-1979 } \\
\text { Toro spring wheat }\end{array}$}} & 104 & 61 & 93 & 125 & 129 & 134 & 148 & 155 & 164 & 222 \\
\hline & & & & & & & & 111 & 60 & 87 & 119 & 123 & 127 & 141 & 149 & 157 & 215 \\
\hline & & & & & & & & 118 & 55 & 81 & 113 & 117 & 121 & 135 & 143 & 151 & 209 \\
\hline \multirow[t]{2}{*}{ S } & \multirow[t]{2}{*}{$E$} & & \multirow[t]{2}{*}{39} & \multirow{2}{*}{\multicolumn{2}{|c|}{45}} & \multirow[t]{2}{*}{61} & \multirow[t]{2}{*}{91} & 125 & 49 & 79 & 107 & 111 & 116 & 129 & 137 & 145 & 203 \\
\hline & & & & & & & & 201 & 43 & 73 & 101 & 105 & 110 & 123 & 131 & 139 & 196 \\
\hline 1120 & 87 & 144 & 197 & & 08 & 215 & 27 & 208 & 38 & 68 & 96 & 99 & 104 & 117 & 127 & 135 & 192 \\
\hline 306 & 32 & 60 & 100 & & 10 & 119 & 17 & 215 & 32 & 62 & 91 & 95 & 99 & 110 & 120 & 128 & 185 \\
\hline 319 & 25 & 50 & 91 & & 99 & 107 & 160 & 222 & 29 & 56 & 85 & 89 & 93 & 104 & 115 & 124 & 181 \\
\hline 402 & 17 & 39 & 79 & & 88 & 95 & 151 & 301 & 27 & 50 & 79 & 83 & 87 & 99 & 112 & 122 & 179 \\
\hline 412 & 13 & 32 & 71 & & 81 & 89 & 143 & 315 & 25 & 44 & 73 & 80 & 86 & 104 & 121 & 129 & 182 \\
\hline 423 & 17 & 29 & 68 & & 73 & 85 & 13 & & & & & & & & & & \\
\hline 504 & 10 & 22 & 59 & & 69 & 16 & 12 & & & & & & & & & & \\
\hline 516 & 9 & 19 & 56 & & 64 & 73 & 12 & & & & & & & & & & \\
\hline 529 & 5 & 17 & 49 & & 59 & 67 & 119 & & & & & & & & & & \\
\hline
\end{tabular}

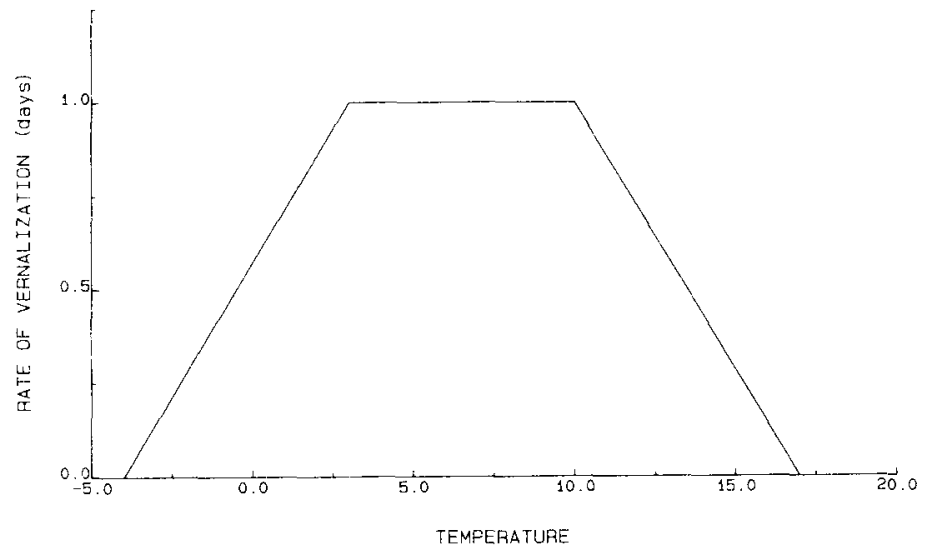



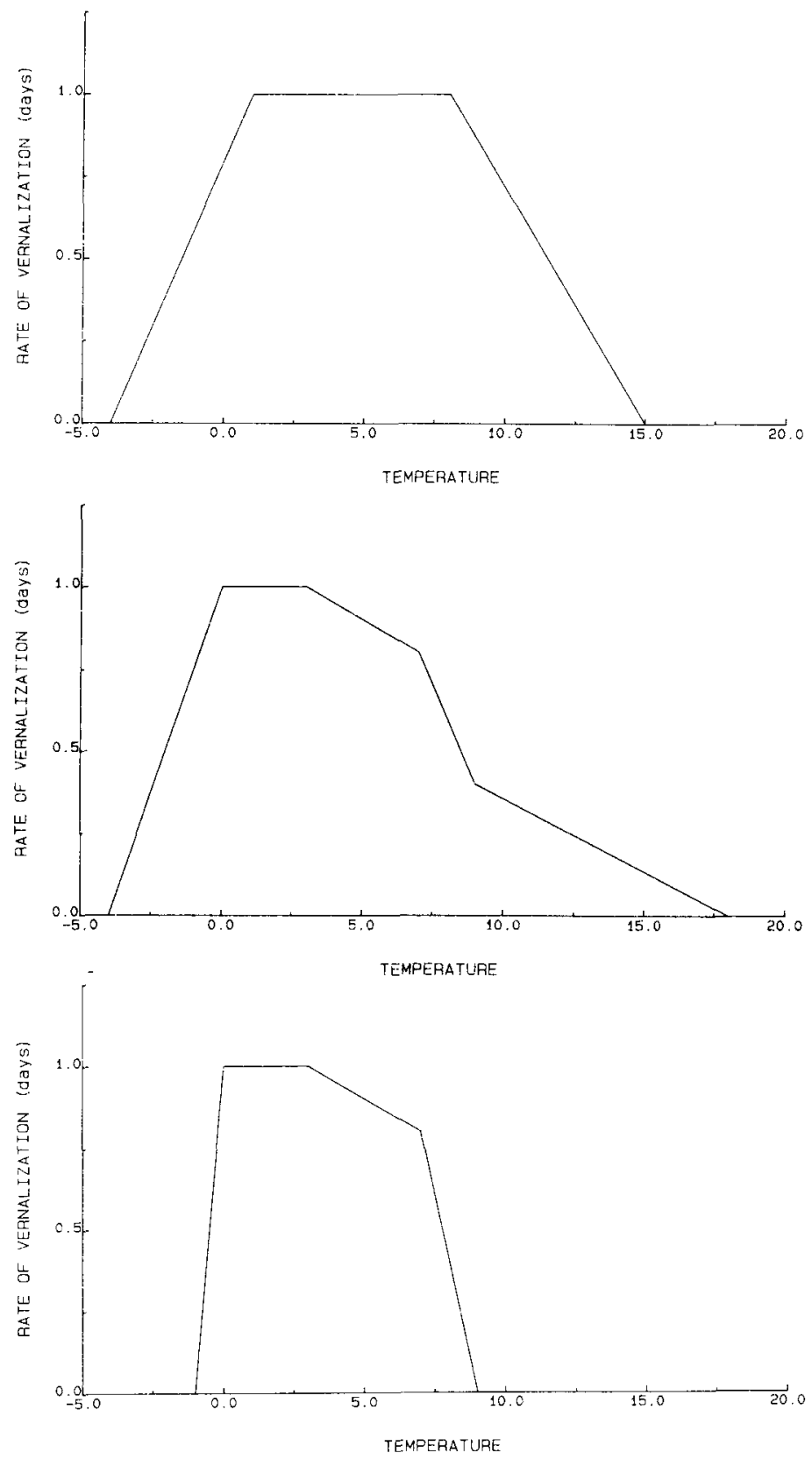

Fig. 1. The effectiveness of temperature $\left({ }^{\circ} \mathrm{C}\right)$ on the vernalization process. a (opposite page): after Lunsden (1980).

b (top above): modified after Hansel (1953).

c (middle above): after Maas \& Arkin (1980).

$\mathrm{d}$ (bottom above): modification of $\mathrm{c}$. 


\section{Method for validation of the AFRC model}

To validate the AFRC model, data from the experiments with Caribo winter wheat were used. This data set has the advantage of having the same variety in two different seasons with a total of 35 sowing dates. The experiments with the varieties Lely and Toro were used later on to test the performance of the adapted phenology model against an independent data set.

As a criterion for performance of the model with different parameter values, the prediction of anthesis was used. Anthesis is a developmental stage which can be determined fairly accurately and thus it is probably the stage which is least affected by observational errors. Performance of a specific set of parameters is given as the coefficient of variation (CV; standard deviation expressed as a percentage of the mean value) for the thermal time ( $\mathrm{Tt}$ ) from sowing to anthesis as calculated by the model. CV values were computed for both years and the total of sowings with a weighted formula to compensate for different numbers of sowings per year.

If the model is required to predict the date of anthesis with a deviation of at most two days $(P=0.10)$, the maximum $C V$ value acceptable would be about $2 \%$, assuming an average temperature at anthesis of about $16^{\circ} \mathrm{C}$ and a normal distribution of $\mathrm{Tt}$ at anthesis.

\section{Results of simulation}

In Table 2 the results of simulation runs are given. For each set of parameters mean thermal time ( $\mathrm{Tt})$ at anthesis and coefficients of variation $(\mathrm{CV})$ are given for both seasons separately and for the total set of sowing dates.

In Run 1, shown in Table 2, no corrections for vernalization and photoperiod were made. The mean temperature sums (above a minimum temperature of $1^{\circ} \mathrm{C}$ ) at anthesis for the two years differ by $50{ }^{\circ} \mathrm{C} \cdot \mathrm{d}$, and $\mathrm{CV}$ values are large. In Run 2 , in which the original AFRC phenology model as described by Weir et al. (1984) is used, the difference between $\mathrm{Tt} 78$ and $\mathrm{Tt} 79$ as well as the $\mathrm{CV}$ values are decreased, although the CV values are above $2 \%$. In order to improve the fit of the model to the data for Caribo the values of certain parameters in the model were changed.

In the AFRC model the thermal time of emergence is $148^{\circ} \mathrm{C} \cdot \mathrm{d}$. For our data-set the average temperature sum (base $1{ }^{\circ} \mathrm{C}$ ) at emergence was $133{ }^{\circ} \mathrm{C} \cdot \mathrm{d}$ in 1978 and $113{ }^{\circ} \mathrm{C} \cdot \mathrm{d}$ in 1979 . These values agree better with a later version of the AFRC model (J. R. Porter, pers. comm.) where a value of $125^{\circ} \mathrm{C} \cdot \mathrm{d}$ was used. In this later version the duration of the period between emergence and double ridge stage was set at $270^{\circ} \mathrm{C} \cdot \mathrm{d}$ as opposed to the value of $284^{\circ} \mathrm{C} \cdot \mathrm{d}$ in Weir et al. (1984). The results of using $125^{\circ} \mathrm{C} \cdot \mathrm{d}$ for emergence and $395^{\circ} \mathrm{C} \cdot \mathrm{d}$ for double ridge are shown in Run 3 . The CV values are smaller than those found in Run 2.

In these runs the CV value of thermal time at anthesis is used as a measure of success of the method used to predict the date of anthesis. However, these CV values do not show trends in deviation or which sowings are associated with the largest part of the variation. A graphic representation of thermal time at anthesis as obtained by Run 3 is given in Fig. $2 \mathrm{a}$. It shows that much of the remaining variation in $\mathrm{Tt}$ is 
Table 2. Mean thermal time $\left({ }^{\circ} \mathrm{C} \cdot \mathrm{d}\right)$ at anthesis and coefficients of variation $(\%)$ of the Caribo data-set for the season 1978 (Tt78, CV78), 1979 (Tt79, CV79) and for the total data set (Tt, CV). A run number corresponds with a specific set of parameters as described in the text (E: emergence, DR: double ridge stage, Fv: correction factor for vernalization).

\begin{tabular}{lrrrrrrl}
\hline Run & Tt78 & Tt79 & \multicolumn{1}{c}{ Tt } & CV78 & CV79 & CV & Short description \\
1 & 1265 & 1216 & 1241 & 20.7 & 14.5 & 17.5 & Tt without corrections \\
2 & 925 & 927 & 926 & 6.7 & 2.8 & 5.0 & original AFRC model \\
3 & 906 & 910 & 908 & 6.5 & 2.6 & 4.8 & E at 125 ${ }^{\circ} \mathrm{C} \cdot \mathrm{d}$, DR at $395{ }^{\circ} \mathrm{C} \cdot \mathrm{d}$ \\
4 & 887 & 888 & 887 & 5.1 & 2.1 & 3.8 & VTR-curve Fig. 1b, Vsat $=33 \mathrm{~d}$ \\
5 & 853 & 853 & 853 & 2.9 & 3.9 & 3.3 & VTR-curve Fig. 1c \\
6 & 874 & 874 & 874 & 3.9 & 2.8 & 3.3 & VTR-curve Fig. 1d \\
7 & 873 & 874 & 874 & 3.0 & 2.8 & 2.8 & Fv fixed at Tt $=3955^{\circ} \mathrm{C} \cdot \mathrm{d}$ \\
8 & 869 & 874 & 872 & 2.0 & 2.8 & 2.3 & Fv fixed at Tt $=270^{\circ} \mathrm{C} \cdot \mathrm{d}$ \\
\hline
\end{tabular}

caused by the earlier and later sowings, which could be caused by an underestimation of the vernalizing effect in those periods, caused by either a too low value for Vsat or an overestimation of the vernalizing effect of rather high temperatures (e.g. above $8{ }^{\circ} \mathrm{C}$ ). A second reason could be the vernalizing effect of short photoperiods, but in separate runs no satisfactory results were obtained when this concept was introduced into the model. That supports the conclusion of Lumsden (1980) that the vernalizing effect of short days is negligible in our climate.

The VTR curve used in the AFRC model (Fig. 1a) was obtained from the work of Hänsel (1953, cited by Lumsden, 1980) on winter rye, but the curve was moved some degrees upward. This is not in accordance with reports that temperatures around $1{ }^{\circ} \mathrm{C}$ are very effective for vernalization of wheat (Ahrens \& Loomis, 1963). With the Caribo data-set better results were expected by using a simplified version of Hänsel's VTR curve (Fig. 1b). In that way the vernalizing effectiveness of temperatures above $8{ }^{\circ} \mathrm{C}$ is reduced and the effect of temperatures around $0{ }^{\circ} \mathrm{C}$ is increased.

The value of Vsat is correlated with the VTR curve; the value of 33 days in the AFRC model was calculated from Hänsel's experiment, who considered plants fully vernalized after 46 days at $1{ }^{\circ} \mathrm{C}$. For the VTR curve of Fig. 1b the original value of 46 days for total vernalization was used. In Run 4 (Table 2) and Fig. $2 b$ the improvement is shown. The result for 1979 is acceptable $(\mathrm{CV}=2.1)$, but for 1978 the $\mathrm{CV}$ value is still too high. The high value of CV78 is caused mainly by the last sowing (Fig. 2b). This sowing (14 March 1978) reached anthesis 21 days later than the previous sowing and anthesis was irregular, suggesting incomplete vernalization (Gott, 1957). This incomplete vernalization is difficult to explain with the present VTR curve because, according to the model, this last sowing had accumulated 48 optimal vernalizing days before double ridge stage $\left(\mathrm{Tt}=395^{\circ} \mathrm{C} \cdot \mathrm{d}\right)$ was reached.

More recent work on the effect of temperature on the vernalization response is given by Maas \& Arkin (1980). Their VTR curve (Fig. 1c) has been used and the results are given as Run 5 in Table 2 and in Fig. 2c. Compared to Run 4 the 1978 result is better but that for 1979 is worse, due to an overcompensation for vernalization for the first three sowings (1 September, 1 October and 1 November 1976). 
K. REININK, I. JORRITSMA AND A. DARWINKEL
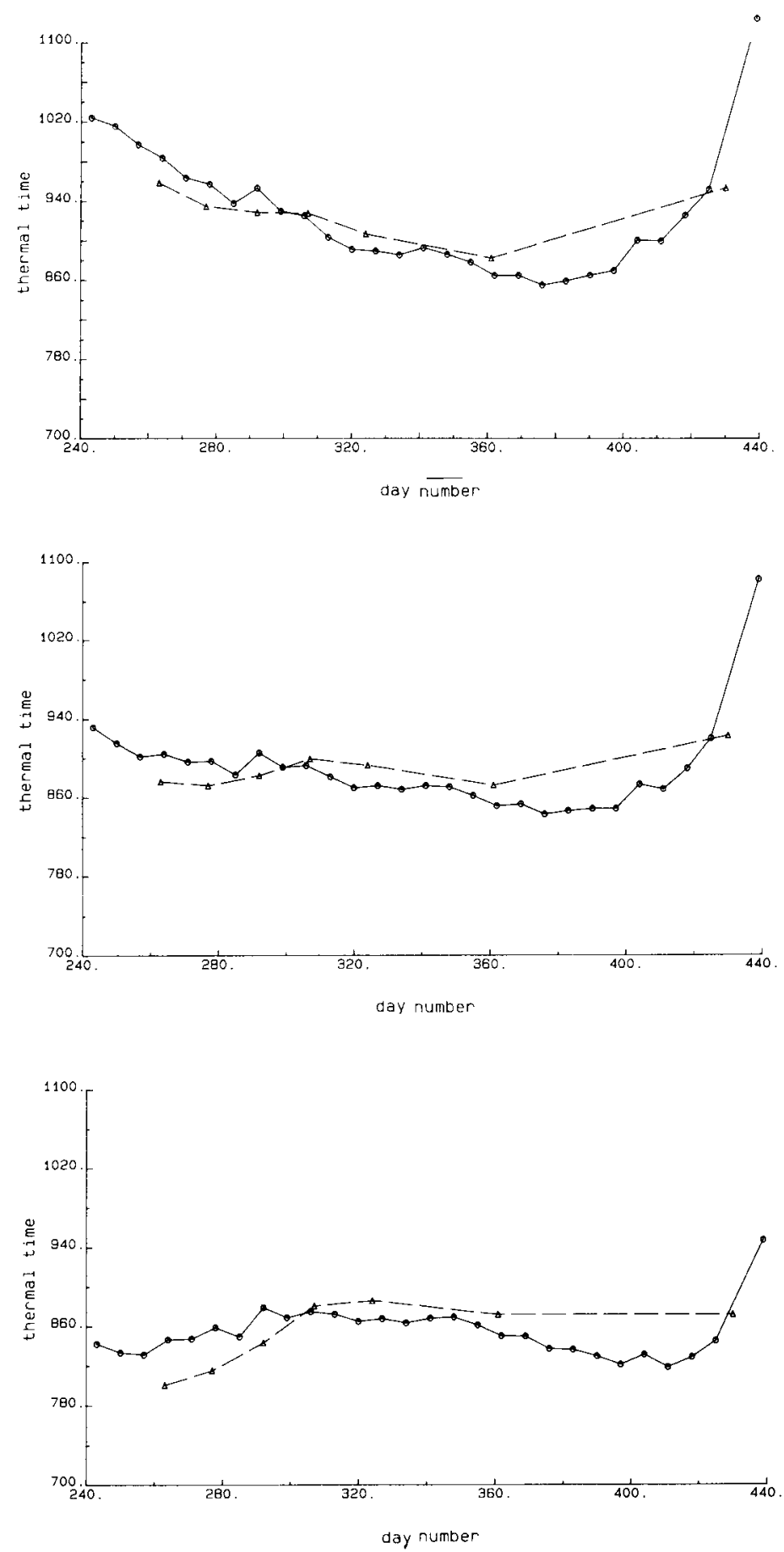


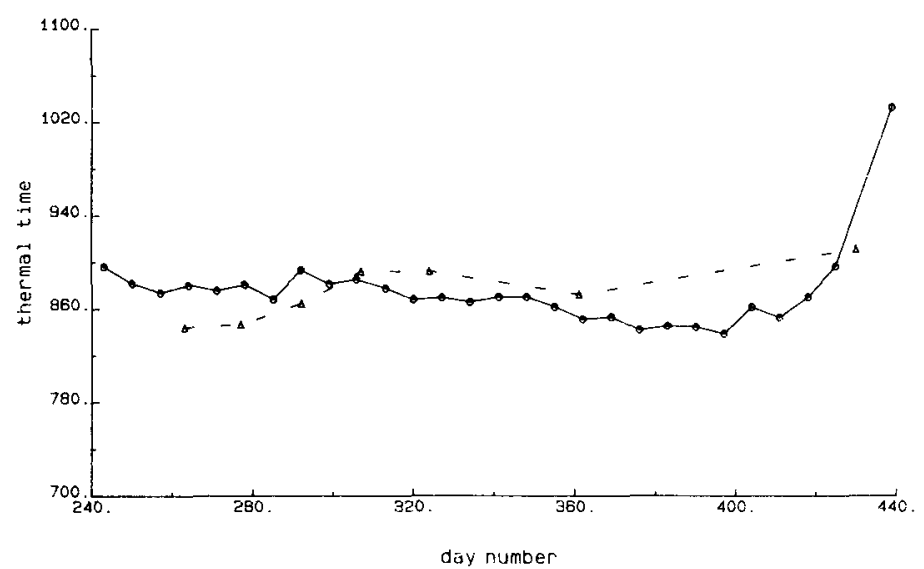

Fig. 2. Relation between sowing date (day number) and thermal time $\left({ }^{\circ} \mathrm{C} \cdot \mathrm{d}\right.$, degree-days) at anthesis with varying vernalization-temperature response (VTR) curves.

a (top, opposite page): VTR curve after Lumsden (1980).

b (middle, opposite page): VTR curve modified after Hansel (1953).

c (bottom, opposite page): VTR curve after Maas \& Arkin (1980).

d (above): VTR curve modified after Maas \& Arkin (1980).

The solid line represents data from the 1978 sowing experiment, the dotted line those from the 1979 experiment.

In the autumn of 1978 , the period before the fourth sowing date (1 December) was warm, with average daily temperatures mostly above $8^{\circ} \mathrm{C}$. Therefore it seems that these temperatures do have some vernalizing effect, less than in the VTR curve of Fig. 1b, but more than proposed by Maas \& Arkin (Fig. 1c). A compromise could be a curve as presented in Fig. 1d, which was applied in Run 6 in Table 2 and resulted in the curves of Fig. 2 d.

Using the VTR curve as given in Fig. 1d the 28th sowing of the 1978 experiment still causes a high amount of variation. In the AFRC model vernalization is completed $(\mathrm{Fv}=1)$ whenever a sufficient number of vernalization days (Vsat) has been accumulated or when double ridge stage is reached $\left(\mathrm{Tt}=395^{\circ} \mathrm{C} \cdot \mathrm{d}\right)$. Our results suggest that if vernalization is incomplete at double ridge, development from this stage till anthesis is delayed, an effect also observed by Gott (1957). Apparently temperatures in the vernalizing range increase the rate of development until a certain phenological stage is reached. When, in the model, the correction factor for state of vernalization (Fv) is maintained at the value it has acquired at the start of the double ridge stage the results as given in Run 7 (Table 2) are obtained. The improved result for 1978 is only the result of the reduction in $\mathrm{Tt}$ of the last sowing from 1031 to $981{ }^{\circ} \mathrm{C} \cdot \mathrm{d}$. The other results did not change. The high values for $\mathrm{Tt}$ at anthesis of the last three sowings of the 1978 experiment (Fig. 2d) seems to suggest that the final value of Fv has to be fixed somewhat earlier than double ridge, e.g. at floral initiation. An early version of the AFRC model defines the stage of floral initiation at $\mathrm{Tt}=270^{\circ} \mathrm{C} \cdot \mathrm{d}$ (Porter, pers. comm., 1982). If this value is used to fix $\mathrm{Fv}$, even better results are obtained, as is shown in Run 8 (Table 2). 
Table 3. Mean thermal time $\left({ }^{\circ} \mathrm{C} \cdot \mathrm{d}\right)$ and coefficients of variation $(\%)$ for some development stages (Decimal Code), using the adapted phenology model. Results of 4 sowing date experiments.

Explanation of stages: E: emergence, 21: main shoot and 1 tiller, 30: pseudostem erection, 31: first node detectable, 32: second node detectable, 39: flag leaf ligule just visible, 45: boots swollen, 61: beginning of anthesis, 91 : maturity.

Experiments: 1) cv. Lely, 6 sowing dates; 2) cv. Caribo, 28 sowing dates; 3) cv. Caribo, 7 sowing dates; 4) cv. Toro, 9 sowing dates.

\begin{tabular}{|c|c|c|c|c|c|c|c|c|}
\hline \multirow[t]{2}{*}{ Stage } & \multicolumn{4}{|c|}{ Mean thermal time $\left({ }^{\circ} \mathrm{C} \cdot \mathrm{d}\right)$} & \multicolumn{4}{|c|}{ Coefficients of variation } \\
\hline & Exp. 1 & Exp. 2 & Exp. 3 & Exp. 4 & Exp. 1 & Exp. 2 & Exp. 3 & Exp. 4 \\
\hline $\mathrm{E}$ & 85 & 127 & 112 & 104 & 37.1 & 7.9 & 10.3 & 16.9 \\
\hline 21 & 187 & 193 & 200 & 233 & 26.2 & 23.1 & 27.4 & 7.8 \\
\hline 30 & 361 & 379 & & . & 37.9 & 24.3 & & . \\
\hline 31 & 485 & 447 & . & . & 10.6 & 6.7 & & . \\
\hline 32 & & 495 & & & & 6.0 & & \\
\hline 39 & 650 & 667 & 671 & 675 & 9.3 & 3.4 & 3.6 & 3.3 \\
\hline 45 & . & 779 & 782 & 779 & & 2.6 & 3.4 & 3.2 \\
\hline 61 & 896 & 869 & 870 & 872 & 0.9 & 1.8 & 2.2 & 2.2 \\
\hline 91 & 1242 & 1224 & 1185 & 1188 & 0.4 & 1.3 & 1.5 & 2.4 \\
\hline
\end{tabular}

Although the CV value for 1979 is still high, the overall result was not significantly improved by further runs. The parameter set of Run 8 was used in further calculations and will be referred to as the 'adapted model'.

Application of the adapted model to the field data given in Table 1 leads to the results as shown in Table 3 . For the spring wheat variety Toro the assumption was made that no vernalization was required $(V s a t=0)$. Development stages before the first node stage (DC31) yield high CV values. Performance of the model for anthesis and for maturity is rather good, with $\mathrm{CV}$ values of about $2 \%$ or less. Values for $\mathrm{Tt}$ at anthesis for variety Caribo are slightly different from those in Run 8 because of a switch in base temperature from $1{ }^{\circ} \mathrm{C}$ to $9{ }^{\circ} \mathrm{C}$ occurring, according to the model, at anthesis. In the final run this switch was made operative at a value of $\mathrm{Tt}$ of $872{ }^{\circ} \mathrm{C} \cdot \mathrm{d}$, which was the mean value for $\mathrm{Tt}$ at anthesis in Run 8 . Results for Toro spring wheat in the 1979 season are very similar to those for the Caribo winter wheat variety grown in the same season.

A large part of the remaining variation in the prediction of the development stages is caused by sowings which have no practical agronomical meaning (e.g. winter wheat sown in spring). A selection was made of those sowing dates which fall within the normal range for Dutch cereal growers. Table 4 shows the results of the adapted phenology model for this restricted data set. For phenology stages above Decimal Code $30 \mathrm{CV}$ values are substantially smaller when the more unusual sowing dates are excluded.

\section{Discussion}

In comparison to the original AFRC model the changes in the adapted model are as follows. 
Table 4. Mean thermal time $\left({ }^{\circ} \mathrm{C} \cdot \mathrm{d}\right)$ and coefficients of variation $(\%)$ for some development stages (Decimal Code), using the adapted phenology model. Results for sowing dates of common agronomical use: winter wheat 20 September-15 December, spring wheat 15 January-15 April.

Explanation of stages: E: emergence, 21: main shoot and 1 tiller, 30: pseudostem erection, 31: first node detectable, 32: second node detectable, 39: flag leaf ligule just visible, 45: boots swollen, 61: beginning of anthesis, 91: maturity.

Experiments: 1) cv. Lely, 3 sowing dates; 2) cv. Caribo, 13 sowing dates; 3) cv. Caribo, 5 sowing dates; 4) $\mathrm{cv}$. Toro, 4 sowing dates.

\begin{tabular}{|c|c|c|c|c|c|c|c|c|}
\hline \multirow[t]{2}{*}{ Stage } & \multicolumn{4}{|c|}{ Mean thermal time $\left({ }^{\circ} \mathrm{C} \cdot \mathrm{d}\right)$} & \multicolumn{4}{|c|}{ Coefficients of variation } \\
\hline & $\overline{\text { Exp. } 1}$ & Exp. 2 & Exp. 3 & Exp. 4 & Exp. 1 & Exp. 2 & Exp. 3 & Exp. 4 \\
\hline$E$ & 71 & 126 & 117 & 110 & 16.0 & 7.0 & 9.2 & 13.3 \\
\hline 21 & 183 & 188 & 188 & 230 & 27.6 & 25.8 & 32.5 & 9.5 \\
\hline 30 & 375 & 397 & . & . & 31.9 & 17.5 & & 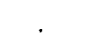 \\
\hline 31 & 492 & 459 & & . & 3.1 & 6.3 & . & . \\
\hline 32 & & 512 & 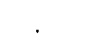 & . & & 4.4 & & \\
\hline 39 & 666 & 687 & 666 & 682 & 5.3 & 1.9 & 2.9 & 2.0 \\
\hline 45 & & 788 & 775 & 794 & & 1.4 & 3.2 & 1.2 \\
\hline 61 & 895 & 875 & 865 & 879 & 0.5 & 0.8 & 2.3 & 0.8 \\
\hline 91 & 1243 & 1221 & 1182 & 1199 & 0.3 & 0.7 & 1.7 & 0.4 \\
\hline
\end{tabular}

- Thermal time at emergence is changed from 148 to $125^{\circ} \mathrm{C} \cdot \mathrm{d}$ and double ridge from 432 to $395{ }^{\circ} \mathrm{C} \cdot \mathrm{d}$.

- The VTR curve is changed from that in Fig. 1a to that in Fig. 1d and concurrently Vsat is changed from 33 to 46 days.

- The state of vernalization is fixed at floral initiation $\left(270{ }^{\circ} \mathrm{C} \cdot \mathrm{d}\right)$ instead of double ridge stage. If the vernalization requirements are not met at floral initiation, the correction factor for state of vernalization $(\mathrm{Fv})$ is not set at 1 , but is maintained at the value acquired at the floral initiation stage. After anthesis no effect of incomplete vernalization upon rate of development is thought to occur. From the literature no clear evidence about the development stage at which the apex becomes insensitive to vernalizing temperatures could be obtained.

- For the spring wheat variety Toro no vernalization requirement was assumed.

These changes improved the prediction of anthesis for the Caribo data-set. This final model was also found to give good results for the experiments not used in adapting the AFRC model. As could be expected the predictive value of the model for stages before the start of stem elongation is low. Excluding sowings with no practical significance substantially improves the prediction of stages after the start of stem elongation (DC 30). However, in the process of adapting the phenology model these extreme sowing dates cannot be excluded as they highlight the weaknesses of the model. The fact that the results improve by excluding extreme sowing dates shows that the model does not yet quantitatively account for all the processes that influence phenological development of the winter wheat crop. However, because for 'normal' sowing dates the model gives good results, it can be used with fair confidence for practical purposes.

In this study most attention was paid to the correction factor for vernalization. 
The effectivity of well-defined temperatures on the vernalization process has been studied by several authors (e.g. Hänsel, 1953; Ahrens \& Loomis, 1963; Trione \& Metzger, 1970). Their results are not conclusive. That could be because of differences in wheat varieties or the species used (Hänsel used rye in his experiment). Our opinion is that the shape of the VTR curve is not or is only slightly variety-dependent and varietal differences mainly originate from differences in Vsat; the number of vernalizing days needed for complete vernalization. Vsat can range from $0 \mathrm{~d}$ for some spring wheats up to values around $46 \mathrm{~d}$ and probably even higher for 'true' winter wheats. The real shape of the VTR curve can only be found by experimentation in controlled environments. In this work a curve was obtained by trial and error, taking previous experimental results into account.

The Dutch variety list (1977) classifies the varieties Caribo and Lely as almost equal in earliness of ear emergence and Caribo as maturing somewhat earlier. Toro is described as late in both aspects. The results of the phenology model show that mean $\mathrm{Tt}$ values for the specified decimal stages of Caribo and Toro are almost equal for the 1979 season. Compared to the 1979 results the results for Caribo in 1978 diverge mainly in thermal time at maturity. The results for the variety Lely diverge even more for anthesis and maturity. As the Lely experiment was the first experiment, in which the observation method was developed, it has undoubtedly a lower accuracy than the last three experiments.

The prediction of the development stages is variety-dependent. However, it may be expected that a group of varieties, which is adapted to a specific environment has more or less similar developmental rhythms. In that case the phenology model could be applied to other varieties without having to make the effort of verification by means of sowing date experiments for every new variety.

\section{References}

Ahrens, J. F. \& W. F. Loomis, 1963. Floral induction and development in winter wheat. Crop Science 3: 463-466.

Baker, C. K., J. N. Gallagher \& J. L. Monteith, 1980. Daylength change and leaf appearance in winter wheat. Plant, Cell and Environment 3: 285-287.

Chujo, H., 1966. Difference in vernalization effect in wheat under various temperatures. Proceedings Crop Science Society of Japan 35: 177-186.

Feekes, W., 1941. De tarwe en haar milieu. Verslag Technische Tarwe Commissie 12: 523-888.

Feiffer, P., G. Lohse \& W. Unger, 1977. Einige neue Aspecte zur Getreideernte. Feldwirtschaft 186 : 254-256.

Gott, M. B., 1957. Vernalization of green plants of a winter wheat. Nature 180: 714-715.

Halloran, G. M. \& A. L. Pennell, 1982. Duration and rate of development phases in wheat in two environments. Annals of Botany 49: 115-121.

Hänsel, H., 1953. Vernalization of winter rye by negative temperatures and the influence of vernalization upon the lamina length of the first and second leaf, in winter rye, spring barley and winter barley. Annals of Botany 17: 417-432.

Keulen, H. van \& N. G. Seligman. Simulation of water use, nitrogen nutrition and growth of a spring wheat crop. Simulation Monographs. Pudoc, Wageningen (in preparation).

Kirby, E. J. M. \& M. Appleyard, 1982a. Cereal development guide. Cereal Unit, National Agricultural Centre, Stoneleigh, England.

Kirby, E. J. M. \& M. Appleyard, 1982b. Cereal plant development: assessment and use. Soil Scientists 
Technical Conference, The nitrogen requirement of cereals, Loughborough University, 6-8 September 1982.

Lumsden, M. E., 1980. The influence of weather on the development of winter wheat. B.Sc. thesis, University of Bath.

Maas, S. J. \& G. F. Arkin, 1980. TAMW: A wheat growth and development simulation model. Texas Agricultural Experiment Station, Blackland Research Center, Temple, Texas.

Trione, E. J. \& R. J. Metzger, 1970. Wheat and barley vernalization in a precise temperature gradient. Crop Science 10: 390-392.

Vos, J., 1981. Effects of temperature and nitrogen supply on post floral growth of wheat; measurements and simulations. Agricultural Research Report 911 . Pudoc, Wageningen.

Weir, A. H., P. L. Braggs, J. R. Porter \& J. H. Rayner, 1984. A winter wheat crop simulation model without water or nutrient limitations. Journal of Agricultural Science, Cambridge 102: 371-382.

Rabbinge, R., C. Sinke \& W. P. Mantel, 1983. Yield loss due to cereal aphids and powdery mildew in winter wheat. Mededeling Faculteit Landbouwwetenschappen Rijksuniversiteit Gent 48/4: 1159-1168.

Zadoks, J. C., T. T. Chang \& C. F. Konzak, 1974. A decimal code for the growth stages of cereals. Weed Research 14: 415-421. 